\title{
AVALIAÇÃO DA QUALIDADE MICROBIOLÓGICA DE LEITE PASTEURIZADO PRODUZIDO NO RIO GRANDE DO SUL
}

\author{
Eduardo Luis Mulinari ${ }^{1}$, Michele Dutra Rosolen ${ }^{2}$, Fernanda Scherer Adami ${ }^{3}$
}

\begin{abstract}
Resumo: $\mathrm{O}$ objetivo do atual estudo foi verificar a qualidade microbiológica de leite pasteurizado quanto à coliformes termotolerantes e Salmonella em amostras analisadas entre os anos de 2012, 2013 e 2014, com o intuito de verificar os diferentes motivos de envio e tipos de fiscalização do laticínio para laboratórios de análises microbiológicas do estado do Rio Grande do Sul (RS). Para a conclusão dos resultados utilizou-se como indicativo de qualidade na produção do leite os parâmetros de Salmonella e coliformes termotolerantes, conforme estabelecido na Resolução RDC n 12 de 2001. Foram analisadas um total de 399 amostras, sendo 87 em 2012, 126 em 2013 e 186 em 2014. Nenhuma amostra apresentou resultados positivos para a análise de Salmonella. Para coliformes termotolerantes apresentaram-se acima do limite de tolerância: 6,9 \% das amostras em 2012,10,3 \% em 2013 e 4,3 \% em 2014. O maior percentual de amostra não-conformes para coliformes termotolerantes foram as com Inspeção do Serviço Municipal. Concluise que a qualidade microbiológica do leite produzido no estado do RS estava de acordo com a legislação, quanto à ausência de Salmonella, no entanto, foram identificadas amostras não-conformes para coliformes termotolerantes, sugerindo a necessidade de rigor nas práticas de higiene, além do cumprimento às boas práticas de fabricação a fim de garantir maior qualidade e segurança do produto final.
\end{abstract}

Palavras-chave: Leite pasteurizado. Qualidade. Coliformes termotolerantes. Salmonella.

\section{EVALUATION OF THE MICROBIOLOGICAL QUALITY OF PASTEURIZED MILK PRODUCED IN RIO GRANDE DO SUL}

Abstract: The objective of the present study was to verify the microbiological quality of pasteurized milk
for thermotolerant coliforms and Salmonella in samples analyzed between the years of 2012, 2013 and
2014 , in order to verify the different reasons for sending and types of dairy inspection for laboratories
Of microbiological analyzes of the state of Rio Grande do Sul (RS). For the conclusion of the results,
the parameters of Salmonella and thermotolerant coliforms were used as indicators of quality in milk
production, as established in Resolution RDC No. 12 of 2001. We analyzed a total of 399 samples, 87 in
2012, 126 in 2013 and 186 in 2014. No samples tested positive for the analysis of Salmonella. For fecal

1 Especialista em Gestão em Segurança Alimentar e Nutricional pelo Centro Universitário UNIVATES.

2 Doutoranda em Ciência e Tecnologia de Alimentos pela Universidade Federal de Pelotas-UFPel.

3 Docente do curso de Nutrição da Univates. 
coliforms showed above the tolerance limit: $6.9 \%$ of the samples in 2012, 10.3\% in 2013 and $4.3 \%$ in 2014. The highest sample percentage of non conform for thermotolerant coliforms were with the Inspection of Municipal Service. It was concluded that the microbiological quality of the milk produced in RS was in accordance with the legislation regarding the absence of Salmonella, however, non conform samples were identified for thermotolerant coliforms, suggesting a need for rigor in hygiene practices, compliance with good manufacturing practices to ensure the highest quality and safety of the final product.

Keywords: Pasteurized milk. Quality. Thermotolerant coliforms. Salmonella.

\section{INTRODUÇÃO}

O leite é um dos alimentos mais completos da natureza em virtude do seu conteúdo de proteínas de alta digestibilidade, além de suas vitaminas, sua gordura e seus sais minerais. Ao mesmo tempo, esses nutrientes servem como fontes de energia para diferentes microrganismos. Por isso, realizar o controle sanitário do rebanho leiteiro, monitorar a higiene durante a ordenha, controlar os equipamentos de refrigeração e adequar a infraestrutura de transporte até os laticínios são aspectos de grande importância para a garantia da qualidade higiênico-sanitária do leite (SALVADOR et al., 2012).

A pasteurização é um processo térmico e tem como objetivo eliminar os microrganismos patogênicos não esporulados, bem como reduzir significativamente a microbiota deteriorante, provocando mínimas alterações na sua composição química (LEITE et al., 2002; TONDO; BARTZ, 2011).

Segundo a Instrução Normativa ${ }^{0} 62$ de 2011, o leite pasteurizado é considerado impróprio para o consumo humano quando a amostra produzida e analisada tenha uma Contagem Padrão em Placas (CPP) acima de $1 \times 10^{5} \mathrm{UFC} / \mathrm{mL}$ ou se existir a presença de Salmonella (BRASIL, 2011).

Para o leite ser destinado ao consumo humano é necessária a realização de diversos processos na sua fabricação, sendo um deles a pasteurização. Esse tratamento tem sido realizado nas indústrias, aplicando-se ao produto a temperatura de $72{ }^{\circ} \mathrm{C}$ a $75^{\circ} \mathrm{C}$, pelo tempo de 15 a 20 segundos (pasteurização com temperaturas altas, High Temperature, Short Time - HTST). O leite também pode ser pasteurizado com temperaturas mais baixas $\left(63^{\circ} \mathrm{C}\right.$ a $\left.65^{\circ} \mathrm{C}\right)$, por 30 minutos; esse tratamento tem sido chamado de pasteurização com temperatura baixa e tempo longo (Low Temperature, Long Time LTLT) (BRASIL, 1997).

Um dos principais grupos de microrganismos indicadores de qualidade do leite são as bactérias do grupo coliformes. Este grupo é dividido entre coliformes totais e coliformes termotolerantes (MORELLI, 2008). Os coliformes totais possuem bactérias que apresentam a capacidade de fermentar a lactose à $30^{\circ} \mathrm{C}$, mediante produção de gazes, e são representados por mais de 20 espécies, sendo algumas encontradas no trato gastrointestinal de humanos e de animais (Escherichia coli) (ROSA, 2012; MADIGAN et al., 2010). Os coliformes termotolerantes, também chamados de fecais, caracterizam- 
se pela capacidade de fermentar a lactose produzindo ácido e gás à temperatura de $45^{\circ} \mathrm{C}$. A presença desses microrganismos está associada a materiais de origem fecal e é indicadora de condições insatisfatórias de higiene (PADUA, 2013).

Salmonella spp. é um dos principais agentes causadores de infecção alimentar no mundo. A infecção causada por S. Enterica pode provocar desordens distintas em seres humanos, sendo exemplos a enterite não-tifoide e a febre tifoide. A transmissão é via fecal-oral, após a ingestão de alimentos de origem animal contaminados, como carnes, ovos e leite (LEVINSON, 2010).

Tendo em vista a importância econômica da cadeia do leite na geração de renda para o estado do Rio Grande do Sul (RS), e do seu distinto valor nutricional(MARTINS, 2005), órgãos fiscalizadores tem exigido qualidade sanitária, especialmente após as fraudes encontradas nos últimos anos. Nesse contexto, o Ministério Público deflagrou ações relacionadas à qualidade do leite, conduzidas a partir de 2011, chamadas de "Operação Leite Compensado".

Portanto, o presente estudo teve como objetivo verificar a qualidade microbiológica de leite pasteurizado quanto à coliformes termotolerantes e Salmonella em amostras analisadas entre os anos de 2012, 2013 e 2014, com o intuito de verificar os diferentes motivos de envio e tipos de fiscalização do laticínio para laboratórios de análises microbiológicas do estado do RS.

\section{MATERIAL E MÉTODOS}

Os resultados das análises de coliformes termotolerantes e Salmonella foram coletados em um banco de dados de um laboratório credenciado no Ministério da Agricultura, Pecuária e Abastecimento (MAPA). Foram analisadas 399 amostras de leite pasteurizado para coliformes termotolerantes e 343 amostras para Salmonella, referentes aos anos de 2012, 2013 e 2014.

As amostras representaram a coleta de 35 laticínios do RS e foram agrupadas segundo o tipo de Inspeção e controle de qualidade da empresa da seguinte maneira: Sistema de Inspeção Federal (SIF), Controle de Qualidade da empresa com Inspeção do Serviço de Inspeção Federal (CQ SIF), Coordenadoria de Inspeção de Produtos de Origem Animal (CISPOA), Controle de Qualidade da empresa com Inspeção da Coordenadoria de Inspeção de Produtos de Origem Animal (CQ CISPOA) e Sistema de Inspeção Municipal (SIM). Todas as análises foram solicitadas pelo fabricante.

A metodologia utilizada para a realização das análises de coliformes termotolerantes seguiu as recomendações da Instrução Normativa no 62, do MAPA (BRASIL, 2003). Iniciou-se o processo transferindo $25 \mathrm{~mL}$ da amostra de leite para um saco de stomacher e adicionando $225 \mathrm{~mL}$ do diluente peptona salina $0,1 \%$, seguido de homogeneização. A inoculação foi realizada em três séries de três tubos contendo caldo Lauryl Sulfato Triptose (LST) duplo e LST simples. Na primeira série de tubos foi adicionado $10 \mathrm{~mL}$ 
da amostra em $10 \mathrm{~mL}$ de LST duplo, na segunda série adicionou-se $1 \mathrm{~mL}$ da amostra em $10 \mathrm{~mL}$ de caldo LST simples e na terceira série adicionou-se $0,1 \mathrm{~mL}$ da amostra em $10 \mathrm{~mL}$ de caldo LST simples. A incubação foi realizada por 48 horas a $37,0 \pm 1,0^{\circ} \mathrm{C}$ (BRASIL, 2003).

A leitura foi realizada após a incubação, sendo considerados positivos os tubos de Duhran que apresentaram turbidez com presença de gás. Os frascos positivos passam por confirmação em caldo EC, incubados em banho-maria por 48 horas a $45,0 \pm 1,0^{\circ} \mathrm{C}$. $\mathrm{O}$ resultado foi contabilizado conforme o número de tubos positivos, sendo o resultado expresso na tabela de Número Mais Provável (NMP).

A análise de Salmonella foi baseado no método AOAC Official Method 2011.03, utilizando o equipamento MiniVidasBiomerieux ${ }^{\oplus}$.

Retirou-se $25 \mathrm{~mL}$ da amostra e adicionou-se $225 \mathrm{~mL}$ de solução de água peptona salina tamponada $1 \%$ em um saco de stomacher esterilizado e realizou-se a homogeneização por 1 minuto. Após este período, foi realizada a incubação da mistura à temperatura de $37,0 \pm 1,0^{\circ} \mathrm{C}$ por 24 horas \pm 6 horas. Uma alíquota de $0,5 \mathrm{~mL}$ da solução foi submetida a uma temperatura de $121^{\circ} \mathrm{C}$ no equipamento Heatand Go por 15 minutos. Após a solução foi transferida para o equipamento MiniVidas, onde foi realizada a leitura. Os resultados obtidos são qualitativos, ou seja, presença ou ausência.

Foram calculadas as frequências absolutas (n) e relativas (\%) para as variáveis qualitativas analisadas no presente estudo. Foi realizada a comparação das amostras quanto à conformidade das enumerações de termotolerantes e a presença de Salmonella de acordo com o período e a origem a partir do teste Qui-Quadrado. As análises foram realizadas no pacote estatístico Statistical Package for Social Science (SPSS) 18.0, sendo considerados significativos os valores de $\mathrm{p} \leq 0,05$.

\section{RESULTADOS E DISCUSSÃO}

Foram analisadas 399 amostras de leite pasteurizado para coliformes termotolerantes, dentre as quais $21,8 \%$ foram coletadas em $2012,31,6 \%$ coletadas em 2013 e 46,6\% reunidas em 2014.

No que diz respeito à origem das amostras e à sua fiscalização, $13,3 \%$ eram do SIF ( $\mathrm{n}=53), 37,6 \%(\mathrm{n}=150)$ do CISPOA, 26,1\% ( $\mathrm{n}=104)$ do CQ SIF, 4,5\% ( $\mathrm{n}=18)$ do CQ CISPOA e $18,5 \%$ (n=74) do SIM.

A presença de Salmonella não foi identificada em nenhuma das amostras analisadas. Houve também a verificação quanto a conformidade de coliformes termotolerantes, sendo a maioria considerada conforme ( $\mathrm{n}=372 ; 93,2 \%)$.

Cabe salientar que os coliformes termotolerantes são indicadores higiênicosanitários (BEZERRA et al., 2012), portanto, torna-se fundamental a observação e respeito às boas práticas de fabricação a fim de garantir a segurança do produto. 
Não houve diferença na frequência de amostras contaminadas ou não com Salmonella e coliformes termotolerantes entre os anos de 2012, 2013 e 2014, conforme apresentado na Tabela 1.

Entretanto, quanto a origem de fiscalização apresentou diferença significativa na frequência relativa de conformidade de coliformes termotolerantes das amostras analisadas. Conforme demonstrado na Tabela 2, a maior frequência relativa de amostras não conformes foi observada entre aquelas do SIM (17,6\%) seguido pelo CISPOA (7,3\%).

Tabela 1: Frequência relativa de presença de Salmonella e conformidade termotolerantes de amostras de leite de acordo com o período

\begin{tabular}{l|c|c|c|c}
\hline & 2012 & 2013 & 2014 & $\mathrm{p}^{*}$ \\
\hline Salmonella & & & & \\
Ausente & $73(100 \%)$ & $114(100 \%)$ & $155(100 \%)$ & 0,370 \\
Presente & $0(0 \%)$ & $0(0 \%)$ & $0(0 \%)$ & \\
\hline Termotolerante & & & & \\
Conforme & $81(93,1 \%)$ & $113(89,7 \%)$ & $178(95,7 \%)$ & 0,116 \\
Não-conforme & $6(6,9 \%)$ & $13(10,3 \%)$ & $8(4,3 \%)$ & \\
\hline
\end{tabular}

Obs.: * teste Qui-quadrado

Tabela 2: Frequência relativa de presença de Salmonella e conformidade de coliformes termotolerantes de amostras de leite de acordo com a origem

\begin{tabular}{l|c|c|c|c|c|c}
\hline & SIF & CISPOA & CQSIF & $\begin{array}{c}\text { CQCIS- } \\
\text { POA }\end{array}$ & SIM & $\mathbf{p}^{*}$ \\
\hline $\begin{array}{l}\text { Salmonella } \\
\text { Ausente }\end{array}$ & $\begin{array}{c}46(100 \%) \\
\text { Presente }\end{array}$ & $\begin{array}{c}148(100 \%) \\
0(0 \%)\end{array}$ & $\begin{array}{c}73(100 \%) \\
0(0 \%)\end{array}$ & $\begin{array}{c}14(100 \%) \\
0(0 \%)\end{array}$ & $\begin{array}{c}61(100 \%) \\
0(0 \%)\end{array}$ & 0,860 \\
\hline $\begin{array}{c}\text { Termotolerante } \\
\text { Conforme }\end{array}$ & $\begin{array}{c}52(98,1 \%) \\
\text { Não-conforme }\end{array}$ & $\begin{array}{c}139(9,9 \%) \\
11(7,3 \%)\end{array}$ & $\begin{array}{c}103(99 \%) \\
1(1 \%)\end{array}$ & $\begin{array}{c}17(94,4 \%) \\
1(5,6 \%)\end{array}$ & $\begin{array}{c}6(82,4 \%) \\
13(17,6 \%)\end{array}$ & $<0,001$ \\
\hline
\end{tabular}

Obs.: * teste Qui-quadrado

Moura (2012) realizou um trabalho no estado do Ceará em leites pasteurizados tipo "C", destinados ao programa "Leite é Saúde", e observou que 31,7\% das amostras apresentavam-se fora do padrão para coliformes termotolerantes e $14,1 \%$ com presença de Salmonella, resultados superiores aos encontrados no atual estudo. Assim como o estudo realizado em Alagoas, por Silva et al. (2008) e em Salvador/BA por Leite et al. (2002), com leite pasteurizado do tipo "C", no qual 52,3\% e 35\% das amostras, respectivamente, estavam acima do limite permitido para coliformes termotolerantes.

Ataíde et al. (2008), em estudo desenvolvido no estado da Paraíba, e Bricio et al. (2005), no estado do Rio de Janeiro, analisaram a qualidade microbiológica do leite 
pasteurizado e observaram que $28 \%$ e $11,1 \%$ das amostras, respectivamente, mostraram a presença de coliformes termotolerantes, resultados superiores ao atual estudo. Em relação à análise de Salmonella, os resultados foram negativos para totalidade das amostras, em ambos os estudos.

Zoccheet al. (2002) analisaram um total de 40 amostras leite pasteurizado de empresas de Palotina/PR, com o objetivo de verificar a qualidade das amostras produzidas na cidade e concluíram que somente $10 \%$ (4) apresentaram resultados positivos para coliformes termotolerantes. Tendo em vista que a quantidade de microrganismos encontrados no leite cru influencia na eficiência do processo de pasteurização, práticas inadequadas na ordenha armazenamento e a intensa manipulação do leite pode ser uma das principais causas de contaminação desse alimento.

O presente estudo observou maior frequência relativa de amostras nãoconformes entre aquelas fiscalizadas pelo SIM, possivelmente em virtude do seu papel regulador como órgão de inspeção e de fiscalização, atuando em empresas de pequeno porte nas quais as práticas de higiene e qualidade da matéria-prima ainda são pouco esclarecidas. Da mesma forma, as amostras fiscalizadas pelo CISPOA apresentaram não-conformidades, indicando a importância do controle higiênicosanitário em estabelecimentos que industrializam alimentos de origem animal. Cabe destacar a importância desses órgãos na coibição de práticas irregulares e na criação de oportunidades aos pequenos empreendedores de se estabelecerem, contribuindo para a regularização dessa atividade às normas vigentes, assim como para a economia local com a geração de empregos e de receita (LOMBARDI; REZENDE, 2014).

As ações do Ministério Público na cadeia produtiva do leite e de produtos lácteos, em meados de 2012, constatou diversas irregularidades, dentre elas, a adulteração do leite. A partir disso, houve o aumento do controle por parte das empresas no número de amostras fiscalizadas. Destaca-se que grande parte do leite adulterado estava impróprio para consumo, por este motivo, foram adicionadas a ele substâncias não permitidas para consumo humano, de forma a mascarar o produto. Tendo em vista que os serviços de inspeção possuem como objetivo o controle da qualidade dos produtos de origem animal (MIORELLI, 2010), os resultados apresentados no presente trabalho indicam a necessidade de ferramentas de controle mais rigorosas sobre estes produtos.

Além disso, a inspeção e o monitoramento da sanidade do rebanho, do local e dos procedimentos de higiene, são indispensáveis para a segurança dos produtos. A Inspeção Municipal atua fiscalizando indústrias que praticam o comércio de produtos dentro dos municípios, enquanto que a Inspeção Estadual fiscaliza indústrias com o comércio intermunicipal, dentro do estado de origem (BRASIL, 1998). Os resultados apresentados indicam distintos níveis e métodos na fiscalização dos diferentes órgãos responsáveis. 


\section{CONCLUSÃO}

Conclui-se que as amostras analisadas, em relação à Salmonella, apresentaram-se próprias para consumo, e, em relação ao coliforme termotolerante, ainda pode haver melhora. Além disso, não houve diferença significativa na frequência relativa de amostras contaminadas ou não com Salmonella com a análise de contaminação ou não de coliformes termotolerante entre os anos de 2012, 2013 e 2014. O maior número de leites contaminados foi das empresas fiscalizadas pelo SIM. Os resultados sugerem a necessidade de rigor nas práticas de higiene, além do cumprimento às boas práticas de fabricação a fim de garantir maior qualidade e segurança do produto final.

\section{REFERÊNCIAS}

ASSOCIATION OFFICIAL ANALYTICAL CHEMISTS (AOAC). Official Methods Of Analysis. Washington, Dc: Association Official Analytical Chemists.

ATAÍDE et al. Avaliação microbiológica e físico-química durante o processamento do leite pasteurizado. Comunicação Breve, 2008.

BASTOS, M. et al. Inspeção em uma indústria produtora de queijo tipo coalho no estado do Ceará, visando a implantação das boas práticas de fabricação. Revista do Instituto de Laticínios Cândido Tostes, 2001 57:130-136.

BEZERRA MP et al. Avaliação microbiológica e físico química de linguiça toscana no município de Mossoró, RN. Arquivo do Instituto Biológico.2012, 79:297-300.

BRASIL. Ministério da Agricultura Pecuária e Abastecimento - MAPA. Regulamento da Inspeção Industrial e Sanitária de Produtos de Origem Animal - RIISPOA. Brasília, 1997.

BRASIL. Agência Nacional de Vigilância Sanitária. Secretaria de Vigilância Sanitária. Portaria no 1.004, de 11 de dezembro de 1998. (Republicada no DOU. DE 22/03/99).

BRASIL. Instrução Normativa n ${ }^{\circ} .62$ de 26 de agosto de 2003. Análises microbiológicas para controle de produção de origem animal e água. Diário Oficial da União, Brasília, 18 set. 2003.

BRASIL. Ministério da Agricultura, Pecuária e Abastecimento. Instrução Normativa n ${ }^{0} 62$. Diário Oficial da União. Brasília: MAPA, 2011.

BRICIO SML, SILVA CG, FINGER RM. Qualidade bacteriológica do leite pasteurizado tipo $\mathrm{C}$ produzido no estado do Rio de Janeiro. Revista Brasileira Ciência e Veterinária, 2005, 12:124-126.

LEITE et al. Qualidade bacteriológica do leite integral (tipo C) comercializado em Salvador Bahia. Revista Brasileira Saúde Produção Animal.2002, 21-25.

LEVINSON W. Microbiologia Média e Imunologia, 10. Ed. Porto Alegre: Artmes, 2010, $145-146$. 
LOMBARDI EC, REZENDE MTNP. Qualidade microbiológica do leite e do queijo minas frescal processados em duas fábricas de laticínios sob inspeção municipal em Uberlândia MG. Revista Veterinária Notícias. 2014, 20:71-78.

MADIGAN et al. Microbiologia de Brock. 12. ed., Porto Alegre: Artmed, 2010, 818.

MARTINS PC. Oportunidades e desafios para a cadeia produtiva do leite. In: ZOCCAL, R. et al. Orgs.). A inserção do Brasil no mercado internacional de lácteos. Juiz de Fora: Embrapa Gado de Leite, 2005.

\section{MIORELLI A. Inspeção industrial e sanitária de produtos de origem animal}

(Dissertação). Bento Gonçalves: Instituto Federal de Educação Ciência e Tecnologia do Rio Grande do Sul; 2010, 39p.

MORELLI AMF. Escherichia coli O157:H7: Ocorrência em ambiente de produção de leite na microrregião de Viçosa, adesão em diferentes superfícies e resistência a sanitizantes. Tese (Doutorado) - Universidade Federal de Viçosa, MG, 2008

MOURA BM. Análise microbiológica de leite pasteurizado tipo $\mathrm{C}$ destinado ao programa Leite é Saúde no Ceará. Revista Verde de Agroecologia e Desenvolvimento Sustentável, 2012.

PADUA FS. Qualidade, segurança microbiológica e enumeração da microbiota lática autóctone do leite de cabra produzido na região centro-oeste. 2013, 58:42 Dissertação (Mestrado) - Faculdade de Agronomia e Medicina Veterinária da Universidade de Brasília, 2013.

ROSA LS; QUEIROZ MI. Avaliação da qualidade do leite cru e resfriado mediante a aplicação de princípios do APPCC. Revista Ciência e Tecnologia de Alimentos, 2007, 27: 422-430.

SALVADOR FC, BURIN AS, FRIAS AAT, OLIVEIRA FS, FAILA N. Avaliação da qualidade microbiológica do leite pasteurizado comercializado comercializado em ApucaranaPR e região. Revista F@pciência, 2012, 9:30-41.

SILVA et al. Caracterização microbiológica e físico-química de leite pasteurizado destinado ao programa do leite no Estado de Alagoas. Ciência e Tecnologia de Alimentos, 2008.

TONDO EC, BARTZ S. Microbiologia e Sistemas de Gestão da Segurança de Alimentos, Editora Porto Alegre: Meridional, 2011, 33-34.

ZOCCHE et al. Qualidade microbiológica e físico-química do leite pasteurizado produzido na região oeste do Paraná. Archives of Veterinary Science. 2002, 7:59-67. 